\section{Arcobacter butzleri: Underestimated Enteropathogen}

\author{
Valérie Prouzet-Mauléon, ${ }^{*}$ Leila Labadi,* \\ Nathalie Bouges, ${ }^{*}$ Armelle Ménard, $\dagger$ \\ and Francis Mégraud*
}

Molecular methods applied to 2,855 strains of Campylobacter-like organisms received from a surveillance network of Campylobacter infections in France identified 29 Arcobacter butzleri infections. This species ranks fourth for Campylobacteraceae isolation and appears to have the same pathogenic potential as the other species in the genus.

K iehlbauch et al. (1) originally described the species Arcobacter butzleri, previously named Campylobacter butzleri (1), after studying aerotolerant Campylobacter strains from human and veterinary sources. The genus Arcobacter was created in 1992 (2).

A. butzleri is found in environmental samples, and untreated water appears to be a potential source of infection. In industrialized countries, the most important source of human contamination may be food. Indeed, A. butzleri has been isolated in different breeding animals and is present in a great variety of retail meats, including chicken, beef, pork, and lamb, with a high prevalence in poultry (3).

Although the prevalence of this bacterium in animals and food specimens is well documented, including the first publication by Kiehlbauch et al. that implied this newly described species could be an important human pathogen, only a few reports of human infections are found, and most of them were published before 1995. In the Far East, Taylor et al. formally identified A. butzleri in $2.4 \%$ of diarrheal stool samples collected from Thai children (4), and more recently, 2 bacteremia cases were reported in Taiwan and Hong Kong in patients with an underlying disease (liver cirrhosis and gangrenous appendicitis, respectively) $(5,6)$. In a South African study, 15 A. butzleri were identified among 3,877 Campylobacteraceae strains isolated from children's diarrheic stools (7). Reports from Europe are scarce: an outbreak of recurrent abdominal cramps in 10 patients in Italy (8), bacteremia in a newborn in the United Kingdom (9), and 2 cases of severe diarrhea in Germany (10). The recent publication of Vandenberg et al.

*Hôpital Pellegrin, Bordeaux, France; and †Université Victor Segalen Bordeaux 2, Bordeaux, France from Belgium used an Arcobacter-selective medium for stool specimens and found that $A$. butzleri ranked fourth among Campylobacter spp. and Campylobacter-like organisms (11), which stimulated interest to revisit the role of Arcobacter spp. as an agent of enteric infection.

In this study, our goal was to investigate the prevalence of $A$. butzleri with a different approach and to describe the clinical features of A. butzleri infection. We used molecular methods to identify Campylobacter-related organisms collected from a network of clinical laboratories that do not use specific Arcobacter-selective medium. The results nevertheless showed that this bacterium ranks fourth among these organisms.

\section{The Study}

The French surveillance network of human Campylobacter infections is composed of laboratories selected on a voluntary basis (12). The laboratories are randomly located throughout France; 93 are hospital laboratories, and 338 are private laboratories. They send their clinical Campylobacter isolates to the National Reference Center with a completed information sheet concerning the patient and epidemiologic data. The study period was from July 2002 to December 2003, and 2,855 Campylobacterlike strains were studied. In addition to standard phenotypic identification, specific polymerase chain reaction (PCR) assays were carried out to identify C. jejuni, C. coli, or $C$. fetus (13); other isolates were identified by comparing 2 sequences of $400 \mathrm{bp}$ located at both extremities of a 1,100bp fragment of the beginning of the 16S rRNA gene amplified with primers F2-16S-CHPEC (ATCCTGGCTCAGAGTGAACG) and R2-16S-CHPEC (AAGGGCCATGATGACTTGAC) with those of DNA databases by using the BLAST program (http://www.ncbi.nlm.nih.gov/blast/). An identification at the species level was regarded as correct when $\geq 99 \%$ identity was seen with only 1 species. The species distribution from stool samples was as follows: 2,114 C. jejuni (78.9\%), 486 C. coli (18.1\%), 36 C. fetus (1.3\%), 27 A. butzleri (1.0\%), 8 C. lari (0.3\%), 4 C. upsaliensis (0.1\%), 2 C. hyointestinalis, and 1 Helicobacter canadensis. From 177 nonstool samples, we detected 2 A. butzleri.

Almost the entire 16S rRNA gene, 1,450 bp, was sequenced for 9 A. butzleri to study its homogeneity because only 5 sequences are in the databank (accession nos. AF314538, AY621116, L14626, U34386, U34388). The intraspecies variability was only $0.4 \%$ (6/1,430 bp) among the $14 \mathrm{~A}$. butzleri sequences. Comparison of these sequences with those of 4 A. cryaerophilus (AY314755, L14624, U34387, U25805), 1 A. skirrowii (L14625), and 1 A. nitrofigilis (L14627) showed that interspecies variability concerned 14 bp out of 1,430. The Arcobacter sequences differed considerably from those of 
Campylobacter spp., with only $86.2 \%$ identity with C. coli (AY621115) and 85.6\% identity with C. fetus (AY621110), 2 species that can be phenotypically confounded with $A$. butzleri.

Twenty-seven of the 29 A. butzleri strains were isolated from feces of patients with gastroenteritis, whereas 1 strain was isolated from peritonitis pus and another from a blood culture specimen. The 27 Arcobacter strains from stools were isolated in 23 different laboratories. Most of them (n = 15) used Campylosel (bioMérieux, Marcy l'Etoile, France) incubated at $37^{\circ} \mathrm{C}$ for 2 to 3 days. Six used Karmali agar incubated at $37^{\circ} \mathrm{C}$ for 3 to 4 days. The last 2 used Butzler medium and the filtration method, respectively. None of these infections was part of an outbreak. Of the 16 patients with travel information available, only 1 indicated a recent trip, to Turkey. An associated pathogenic organism was described in 1 of 15 cases, but the nature of the associated organism is unknown. Seventeen of the 29 patients were hospitalized. Their age range was 1-89 years, with an average of 54 years. Seventeen patients (59\%) were male. Detailed clinical information was obtained for 19 patients and is shown in the Table. Eighteen of 19 patients had diarrhea, including the patient with bacteremia; 11 of 15 had abdominal pain; 4 of 15 had bloody stools, including the patient with $A$. butzleri bacteremia; 2 of 14 patients vomited; and 5 of 17 patients had fever. Acute renal failure developed in 2 patients, 1 associated with pyelonephritis. Concerning the 17 other cases for which information was available, severe clinical symptoms (anorexia, weight loss, asthenia) were described for 10 patients.

The duration of symptoms without treatment was variable, from 2 days to several weeks. Antimicrobial drug therapy was administered in 5 cases, and infection was eradicated a few days later (Table). In all cases, the strains were susceptible to the antimicrobial agent used (amoxicillin, ofloxacin, ciprofloxacin [twice], amoxicillin-clavulanate).

\section{Conclusions}

During an 18-month period, 2,855 strains of Campylobacter-like organisms were identified at the species level by using phenotypic and molecular tools. Molecular methods permitted the identification of 29 A. butzleri, i.e., $1 \%$ of the strains studied and also $1 \%$ of the 2,678 isolates from stools, which makes this species the fourth most frequently isolated Campylobacteraceae in human clinical samples in France, before $C$. lari and $C$. upsaliensis but after $C$. jejuni, C. coli, and C. fetus. Our results agree with those of Vandenberg et al. (11) who also found A. butzleri in fourth position for Campylobacter-like isolates from stool specimens. However, their results were obtained in a different context: only 1 laboratory was involved for 8 years, and a specific Arcobacter-selective medium was used. A study conducted in Denmark by Engberg et al. (14), also to estimate the prevalence of

\begin{tabular}{|c|c|c|c|c|c|c|c|c|c|}
\hline Patient $^{\star}$ & $\begin{array}{l}\text { Age } \\
\text { (y) }\end{array}$ & Sex & Diarrhea & $\begin{array}{l}\text { Abdominal } \\
\text { pain }\end{array}$ & $\begin{array}{l}\text { Blood in } \\
\text { stool }\end{array}$ & Vomiting & Fever & $\begin{array}{c}\text { General } \\
\text { symptoms }\end{array}$ & $\begin{array}{l}\text { Duration of symptoms } \\
\text { and disease course }\end{array}$ \\
\hline 1 & 88 & $\mathrm{~F}$ & + & + & - & & + & + & Death linked to associated neoplasia \\
\hline 2 & 75 & M & + & + & - & - & - & + & $\begin{array}{l}4 \text { days. Acute renal failure } \\
\text { (treated with amoxicillin) }\end{array}$ \\
\hline 4 & 89 & $\mathrm{~F}$ & + & - & - & - & - & + & $\begin{array}{c}6 \text { weeks. Favorable progress after } \\
\text { treatment with ofloxacin }\end{array}$ \\
\hline 7 & 76 & M & + & + & + & - & - & - & 5 days (treated with ciprofloxacin) \\
\hline 8 & 2 & M & + & - & - & + & - & + & 2 days \\
\hline 10 & 69 & M & + & + & & - & - & + & \\
\hline 11 & 4 & M & + & + & - & - & + & + & Several recurrences in 3 months \\
\hline 12 & 72 & $\mathrm{~F}$ & + & - & + & - & - & - & 3 weeks \\
\hline 15 & 89 & M & + & & - & & & - & \\
\hline 18 & 53 & M & + & + & - & - & - & + & Irritable bowel syndrome \\
\hline 19 & 6 & M & + & + & + & + & + & + & 10 days \\
\hline 20 & 30 & $\mathrm{~F}$ & - & + & - & - & - & - & \\
\hline 21 & 68 & M & + & + & + & - & + & + & \\
\hline 23 & 77 & M & + & & & & - & + & $\begin{array}{l}\text { Several days. Acute renal failure } \\
\text { (treated with ciprofloxacin) }\end{array}$ \\
\hline 25 & 1 & $\mathrm{~F}$ & + & & & & + & + & 3 weeks \\
\hline 26 & 41 & M & + & - & - & - & - & + & $\begin{array}{l}\text { Several days (treated with } \\
\text { amoxicillin-clavulanate) }\end{array}$ \\
\hline 27 & 44 & $\mathrm{~F}$ & + & + & - & - & - & - & \\
\hline 28 & 70 & $\mathrm{~F}$ & + & & & & & & \\
\hline 29 & 83 & $\mathrm{~F}$ & + & + & - & - & - & + & Several days \\
\hline
\end{tabular}


Campylobacter spp. and related bacteria in human fecal samples, did not produce the same results; only $1 \mathrm{~A}$. butzleri was isolated out of 1,376 samples, and no C. lari or $C$. upsaliensis was recovered. The differences between these 3 studies could be explained by differences in geographic distribution of the species, but the difference in isolation methods (selective agar in the Belgian study) or in identification methods (molecular methods in our study) is likely the critical point. While not optimal, Campylobacterselective agars, especially Campylosel, appear to allow the growth of $A$. butzleri. For the other media, a longer incubation period seems necessary. The role of $A$. butzleri in enteric infections is not definitively proven, but its involvement is likely. In at least 14 of 15 cases, no other enteropathogen was detected. In 1 case, a bacteremia with an enteric infection was found. These data are similar to those observed with $C$. jejuni infection. Isolation of $A$. butzleri is more frequent than well-known enteropathogenic Campylobacter spp., e.g., C. upsaliensis and C. lari, when adequate identification is carried out. The prevalence of $A$. butzleri may be underestimated because of false identification as $C$. coli or $C$. fetus. Indeed nearly all of the strains are able to grow at $25^{\circ} \mathrm{C}$, like $C$. fetus, but are resistant to cephalothin like $C$. coli. We found that nearly all of the strains were resistant to nalidixic acid (4 had an intermediary resistance) and susceptible to ciprofloxacin with the disk diffusion method. The choice of a simple method for testing these drugs allows it to be used routinely in clinical laboratories to differentiate such strains phenotypically.

Nevertheless, molecular biology is a powerful tool for diagnosis. We used a 16S rRNA gene sequencing as a global approach for strains that were not C. jejuni, C. coli, or $C$. fetus. We confirmed that the intraspecies variability of $A$. butzleri 16S rRNA gene sequences is low $(0.4 \%)$, lower than that found for C. coli $(1.5 \%)$ or C. lari (2.5\%) (15), and that interspecies variability is high. This approach, which is expensive and difficult to implement, is not accessible to a routine laboratory, but simple phenotypic tests can be applied to detect these microorganisms. The combination of phenotypic tests and selective agar medium will determine the real incidence of $A$. butzleri infection, which will add evidence that $A$. butzleri is an etiologic agent of diarrhea. A determination of the prevalence of A. butzleri in normal stool will also help establish the prevalence of this organism in diarrheal stool.

\section{Acknowledgments}

We thank the laboratories participating in our network in France for sending their Campylobacter strains to the National Reference Center for Campylobacters and Helicobacters.

Dr Prouzet-Mauléon is an engineer at the National Reference Center for Campylobacters and Helicobacters. She is responsible for the analyses and development of molecular methods applied to the diagnosis and characterization of Campylobacteraceae.

\section{References}

1. Kiehlbauch JA, Brenner DJ, Nicholson MA, Baker CN, Patton CM, Steigerwalt AG, et al. Campylobacter butzleri sp. nov. isolated from humans and animals with diarrheal illness. J Clin Microbiol. 1991;29:376-85.

2. Vandamme P, Vancanneyt M, Pot B, Mels L, Hoste B, Dewettinck D, et al. Polyphasic taxonomic study of the emended genus Arcobacter with Arcobacter butzleri comb. nov. and Arcobacter skirrowii sp. nov., an aerotolerant bacterium isolated from veterinary specimens. Int J Syst Bacteriol. 1992;42:344-56.

3. Houf K, De Zutter L, Verbeke B, Van Hoof J, Vandamme P. Molecular characterization of Arcobacter isolates collected in a poultry slaughterhouse. J Food Prot. 2003;66:364-9.

4. Taylor DN, Kiehlbauch JA, Tee W, Pitarangsi C, Echeverria P. Isolation of group 2 aerotolerant Campylobacter species from Thai children with diarrhea. J Infect Dis. 1991;163:1062-7.

5. Yan JJ, Ko WC, Huang AH, Chen HM, Jin YT, Wu JJ. Arcobacter butzleri bacteremia in a patient with liver cirrhosis. J Formos Med Assoc. 2000;99:166-9.

6. Lau SKP, Woo PCY, Teng JLL, Leung KW, Yuen KY. Identification by $16 \mathrm{~S}$ ribosomal RNA gene sequencing of Arcobacter butzleri bacteraemia in a patient with acute gangrenous appendicitis. Mol Pathol. 2002;55:182-5.

7. Lastovica AJ, Skirrow MB. Clinical significance of Campylobacter and related species other than Campylobacter jejuni and C. coli. In: Nachamkin I, Blaser MJ, editors. Campylobacter. 2nd ed. Washington: American Society for Microbiology; 2000. p. 89-120.

8. Vandamme P, Pugina P, Benzi G, van Etterijck R, Vlaes L, Kersters $\mathrm{K}$, et al. Outbreak of recurrent abdominal cramps associated with Arcobacter butzleri in an Italian school. J Clin Microbiol. 1992;30:2335-7.

9. On SL, Stacey A, Smyth J. Isolation of Arcobacter butzleri from a neonate with bacteraemia. J Infect. 1995;31:225-7.

10. Lerner J, Brumberger V, Preac-Mursic V. Severe diarrhea associated with Arcobacter butzleri. Eur J Clin Microbiol Infect Dis. 1994;13:660-2.

11. Vandenberg O, Dediste A, Houf K, Ibekwem S, Souayah H, Cadranel S, et al. Arcobacter species in humans. Emerg Infect Dis. 2004;10: 1863-7.

12. Gallay A, Simon F, Megraud F. Surveillance of human Campylobacter infections in France-part 2-implementation of national surveillance. Euro Surveill. 2003;8:218.

13. Menard A, Dachet F, Prouzet-Mauleon V, Oleastro M, Megraud F. Development of a real-time fluorescence resonance energy transfer PCR to identify the main pathogenic Campylobacter spp. Clin Microbiol Infect. 2005;11:281-7.

14. Engberg J, On SLW, Harrington CS, Gerner Smidt P. Prevalence of Campylobacter, Arcobacter, Helicobacter, and Sutterella spp. in human fecal samples as estimated by a reevaluation of isolation methods for campylobacters. J Clin Microbiol. 2000;38:286-91.

15. Gorkiewicz G, Feierl G, Schober C, Dieber F, Kofer J, Zechner R, et al. Species-specific identification of campylobacters by partial $16 \mathrm{~S}$ rRNA gene sequencing. J Clin Microbiol. 2003;41:2537-46.

Address for correspondence: Francis Mégraud, Laboratoire de Bactériologie, Hôpital Pellegrin, Place Amélie Raba Léon, 33076 Bordeaux, France; fax: 33-5-56-79-60-18; email: francis.megraud@chubordeaux.fr 